\title{
How to think about interprofessional competence: A metacognitive model
}

\author{
Margareta Wilhelmsson, Staffan Pelling, Lars Uhlin, Lars-Ove Dahlgren, \\ Tomas Faresjö and Kenneth Forslund
}

\section{Linköping University Post Print}

N.B.: When citing this work, cite the original article.

Original Publication:

Margareta Wilhelmsson, Staffan Pelling, Lars Uhlin, Lars-Ove Dahlgren, Tomas Faresjö and Kenneth Forslund, How to think about interprofessional competence: A metacognitive model, 2012, Journal of Interprofessional Care, (26), 2, 85-91.

http://dx.doi.org/10.3109/13561820.2011.644644

Copyright: Informa Healthcare http://informahealthcare.com/

Postprint available at: Linköping University Electronic Press

http://urn.kb.se/resolve?urn=urn:nbn:se:liu:diva-75898 


\title{
How to think about interprofessional competence
}

\author{
- a metacognitive framework and model
}

\author{
Margaretha Wilhelmsson ${ }^{1}{ }^{3}$ \\ Staffan Pelling ${ }^{1}{ }^{3}$ \\ Lars Uhlin ${ }^{1}{ }^{3}$ \\ Lars-Owe Dahlgren ${ }^{2}$ \\ Tomas Faresjö ${ }^{1}$ \\ Kenneth Forslund ${ }^{2}$
}

\begin{abstract}
1. Unit of Educational Development and Research, Faculty of Health Sciences, Linköping University, Sweden 2. Department of Behavioural Sciences and Learning, Faculty of Arts and Sciences, Linköping University, Sweden 3. Department of Medicine and Health/Community Medicine, Faculty of Health Sciences, Linköping University, Sweden
\end{abstract}

Correspondence:

Margaretha Wilhelmsson, Faculty of Health Sciences, Linköping University, Sweden, telephone +46101038675 E-mail margareta.wilhelmsson@liu.se

Key words: Curriculum • Interprofessional education • Metacognition • Professional and

Interprofessional competence 


\title{
HOW TO THINK ABOUT INTERPROFESSIONAL COMPETENCE - A METACOGNITIVE MODEL
}

\begin{abstract}
Different professions meet and work together in teams every day in health and social care. In order to identify and deliver the best quality of care for the patient, teamwork should be both professionally and interprofessionally competent. How can enhanced education prepare team workers to be both professionally and interprofessionally competent? To achieve interprofessional skills and design effective interprofessional curricula, there is a need for metacognitive frameworks focusing on the connection between theories and the problem-solving process and the structure and content of professional competence. The aim of this article is to discuss the need for shared metacognitive structures/models as a tool for securing successful interprofessional learning and developing personal, professional and interprofessional competence to improve the quality of care. A metacognitive model for interprofessional education and practice is presented. This model has been developed as a tool for analysing professional competence on three levels: individual, team and organisation. The model comprises seven basic components of professional competence and the way they are related and interact. Examples of how this metacognitive model can be used early on, in the middle and late in interprofessional education are given.
\end{abstract}

\section{INTRODUCTION}

Health care students are expected to become skilful and professional in their own field. However, modern health care organisations also recognise the importance of 
interprofessional competence (WHO, 1978, 1988, 2006), which may be regarded as an additional aspect of the professional compass. Interprofessional competence may be defined as the ability to collaborate with other professions, to know and understand the importance, functions and roles of others in other professions (Barr, Koppel, Reeves, Hammick and Freeth, 2005). Health professionals who meet and work together in interprofessional teams (IPTs) must manage complex patient/client cases (Stephenson, 2004).

Almost everyone who seeks health care interacts with more than one health profession and the number of professions increases with the complexity of the patient's needs (Headrick, Wilcock and Batalden, 1998). Members in IPTs must collaborate to discover the problem of central importance for the patient, a sort of validity action. Today's patients want a quick diagnosis and treatment and/or rehabilitation and they also want to be kept well informed and may take part in discussions (e.g. Barry, Gurland, Gurland and Mitty, 2009). To be professionally and interprofessionally competent, one must study, train and develop a learning process over time (Wilhelmsson, Pelling, Ludvigsson, Dahlgren, Hammar and Faresjö, 2009). The learning process starts for the student with expectations, knowledge, skills and attitudes and these terms are vital for his or her "readiness" for interprofessional situations (Parsell and Bligh, 1998). Learning about professionalism can provide a generic foundation on which students can build a shared appreciation of intrapersonal, interpersonal and public dimensions of their professional behaviour, parameters and responsibility (Olckers, Gibbs and Duncan, 2007). Personally, professionally and interprofessionally competent individuals are a key prerequisite for 
successful teamwork, but in order to work with complex patient/client cases, they also need additional tools such as metacognitive structures.

The aim of this article is to analyse the need for shared metacognitive structures and models to ensure that professionals and students can be successful in interprofessional education (IPE) which will help them develop personally and professionally to improve the quality of care.

Initially, this article provides a meta-cognitive model related to how one may act as a health care professional. It goes on to illustrate how the model may be used as a tool for designing IPE curricula, which could train students in metacognitive thinking.

\section{DEFINITION OF METACOGNITION}

The concept metacognition comprises both metacognitive knowledge and metacognitive experiences or regulations (Flavell, 1979, 1987). Metacognitive knowledge refers to acquired knowledge about cognitive processes that can be used to control such processes, i.e. metacognitive skills. According to Flavell (1987), metacognitive knowledge can be divided into three categories: knowledge of person variables, task variables and strategy variables.

Metacognition refers to higher order thinking which involves active control over the cognitive processes. Activities such as planning how to approach a given learning task, monitoring comprehension and evaluating progress towards the completion of a task are 
metacognitive in nature. Since metacognition plays a critical role in successful learning, it is important to study metacognitive activity and development to determine how students can be taught to better apply their cognitive and communicative resources through metacognitive control (Livingston, 1997).

The metacognitive domain of research was initially developed within a psychological discourse (Flavell, 1979, 1987). In the present context we would, however, expand the concept to comprise metacognitive processes in groups and also the related phenomena of reflection in and on action (Schön, 1987; Clark, 2009; Sandars; 2009, Wackerhausen, 2009). In an interprofessional context there is a need for reflection on professional as well as interprofessional competence, which calls for a somewhat wider meaning of metacognition. Developing theories of metacognition into the context of IPE could help the interprofessional team (IPT) to think about metacognitive processes. By planning how to think and act in complex situations, the IPT can control the total amount of knowledge and skills within the group and use this for strategic action. Evaluations of these processes will give the team members a wider perspective and more knowledge that is beneficial to the patient.

\section{A METACOGNITIVE MODEL FOR INTERPROFESSIONAL COMPETENCE}

A model has been developed to illustrate how metacognition can be used in interprofessional education. This modified model, initially presented by Forslund (2001), is constructed for the purpose of facilitating description and analysis of professional competence on three levels: the individual or personal level, the team level and the 
organisational level. The model can also be used on an extended and general level directed at a more general illumination of professional competence within a certain occupation.

The metacognitive model consists of seven basic components of professional competence and ways in which they can be related to and influenced by each other (Figure 1).

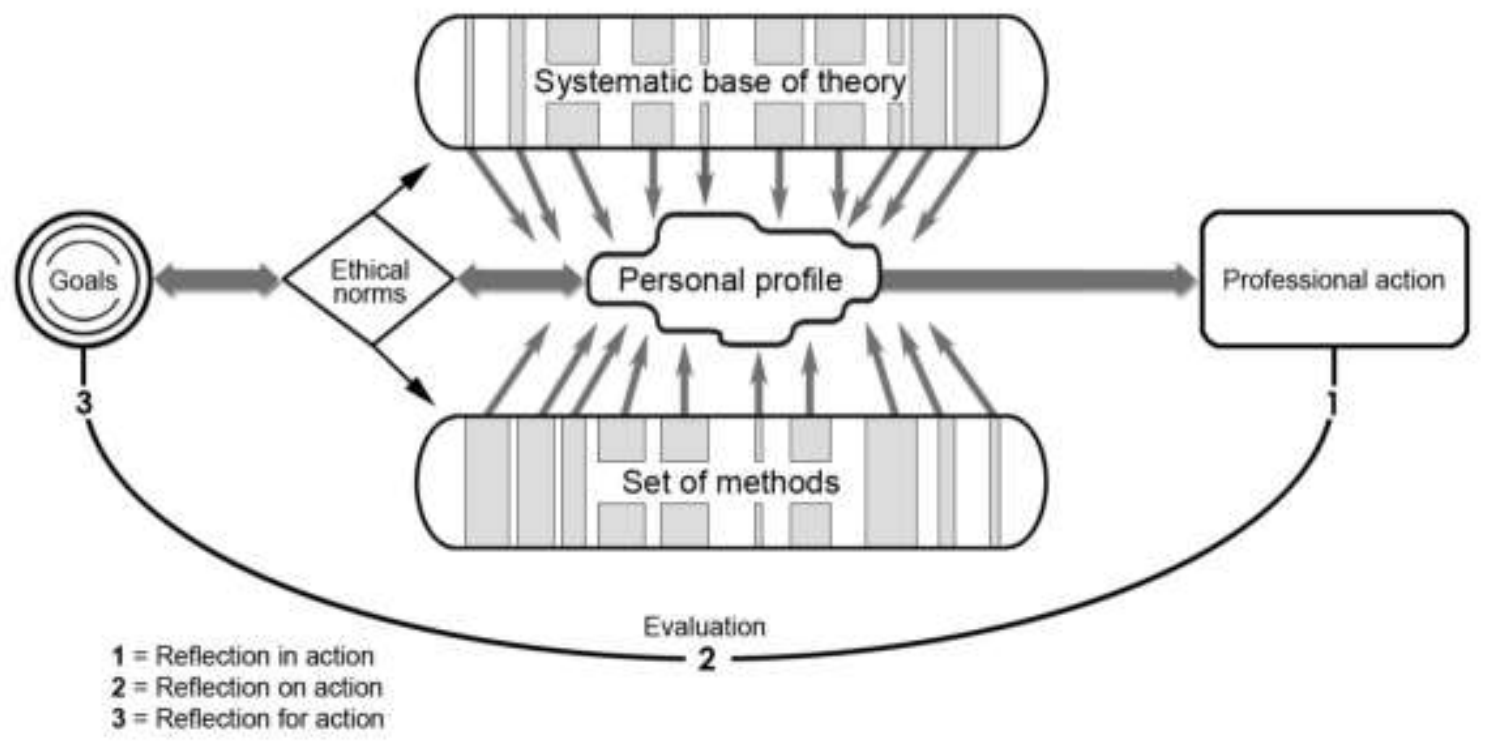

Figure 1. The model comprises seven basic components of professional competence and how they can be related to and influence each other.

\section{Components in the metacognitive model}

A person practicing a profession has a good knowledge of the goals of the work and is also well acquainted with the motives, the theoretical underpinnings and values behind these goals. Goals may have connections to different levels. They refer to laws and regulations as well as goals for a specific assignment. As a part of professionalism, it is 
important to clarify and make explicit the norms that regulate relationships with colleagues and patients. This applies to basic views on human beings.

Professional work in teams has become increasingly more common. The need for explicit communicable ethical norms will increase accordingly. If there are not mutual and explicit ethical codes within professions and between collaborating professions, there is a risk of unnecessary misunderstandings and conflicts.

The relationship between the goals and the ethical norms is of major importance. If they are not consistent, an untenable situation may arise. This situation can either imply that the work and the fulfilment of goals will be undermined by the performance of the professional or that the professional has to give up his/her beliefs with professional deprivation as a result.

In the universe of possible theories within a profession it is necessary to choose theories significant to the goals, tasks, groups of patients and to oneself in the meaning that they can be considered to have great trustworthiness and reliability. To be professionally useful, the theories should, complement and expand one another in a coherent system and constitute a systematic theoretical base for the profession. The systematic theoretical base, together with experience-based knowledge, embodies the concept of "how to think about it" (Cross, 1982), which is the foundation for the knowledge-based analysis and decision-making considered to be characteristic of professional work. The scientific theories together with "practical theories" constitute fundamental cognitive structures for 
professional practice by providing explanatory models. These structures promote the understanding that in practical professional work makes situations and problems recognisable and definable so as to constitute "professional readiness". (See Figure 1).

In a similar way, professionals have a choice of, or may create, working patterns, methods and techniques for their work and thereby acquire a set of methods relevant to the tasks. They should also be relevant to the professional in the sense that the methods are considered powerful and that the abilities, knowledge, skills and experiences needed to use them in a proper way are recognised. This set of methods should correspond to the systematic base of theories and constitute the "how to do it" of the specific profession (Cross, 1982).

The development of a theoretical foundation and a set of methods are dependent on several factors. Extrinsic factors could be the true possibilities of actually being exposed to different theories and varying methods during one's education and training, the degree to which the training is based on modelling of apprenticeship learning, existing professional cultures that the trainee will meet, etc. The goals and the ethical norms are especially important determinants when choosing theories and methods for future professional work.

One's personality and previous knowledge and experiences are intrinsic factors crucial for the kinds of theories and methods that will tend to attract attention and be accepted and integrated in one's emerging professional identity. It is reasonable to plead for a view of 
professions where the goals for the work, the development of an ethical code and access to certain theories and methods along with personality traits and personal experiences, perhaps aided by professionals serving as models, will constitute, on an individual level, a personal profile, in practicing the profession. It is also possible to assume that work in a team develops its own personal profile just as an organisation or an institution with its unique combination of activities, competence and staff can develop a personal profile. Thus, to a great extent, the personal profile determines the behaviour of the professionals, i.e. the professional action in different situations and it will thereby have a great influence on professional decision-making.

In this model, evaluation is a continuous critical examination of actions and results in the workplace. It is a formative procedure where the experiences of what works or not and conclusions concerning the future become a direct input for expanding and enhancing professional competence. Schön (1987), described reflection in action where the professional in direct contact with the problem evaluates in a direct professional action, this could be seen as a part of evaluation.

Another part of evaluation is reflection on action (Schön, 1987) and implies a more complete analysis of what actually happened in relation to all parts of the professional scheme. A third part of evaluation could be reflection for action and deals with a translation of experiences from another evaluation to an action-centred planning of work. Evaluations often identify areas where knowledge or skills are needed and will thereby also help to define needs for consultation, education and training. Continuous evaluation 
is the most powerful way to maintain, expand and enhance professional competence. (See Figure 1).

\section{Personal, professional and interprofessional development}

Personal development in education is a learning process involving experiences, knowledge, skills and the outcomes leading to a change in attitudes (Parsell and Bligh, 1998). Therefore, students must be trained during their education in, for example, reflection on their knowledge and skills, lifelong learning, personal learning style, "thinking about thinking", i.e. metacognition, personal norms, values, morals, ideologies and attitudes, and fostered to be personally competent.

The learning processes for becoming professionally competent can be described as acquiring specific knowledge and skills such as "professional models" or "cognitive maps", the knowledge base underlying a particular profession (Petrie, 1976; Clark, 2006). Cognitive maps constitute the entire paradigmatic and conceptual apparatus used by a profession (Petrie, 1976; Clark, 2006). In addition to cognitive maps, professions have normative maps, including roles, culture, norms, standards and values in the profession. Specific methods and tools for diagnosing and evaluating are also important parts of professional competence. 
The learning processes for becoming interprofessionally competent cannot be separated from the process of becoming professional, but are described as sharing knowledge with other professions, a common language for communication and general working methods. These include problem solving, metacognitive structures, which underpin interprofessional teamwork, and co-operation in IPTs to find the best quality of care for the patient or guide intelligent acting. John Dewey described intelligent acting as working through reflection, problem solving, analysing and critical thinking (Hartman, Lundgren and Hartman, 2004).

There are several approaches and frameworks proposed to define interprofessional capabilities. One is using a grounded theory approach, The Interprofessional Capability Framework, United Kingdom, that defined interprofessional capabilities as comprising four key domains: knowing in practice, ethical practice, interprofessional learning and reflection (learning) (Walsh, Gordon, Marshall, Wilson and Hunt, 2008). In contrast, another approach from The British Columbia Competency Framework for Interprofessional Collaboration, Canada (Wood, Flavell, Vanstolk, Brainbridge and Nasmith, 2009) is organised into three domains: interpersonal communication skills, patient-centred and family focused care and collaborative practice (collaborative decision-making, roles and responsibilities, team functioning and continuous quality improvement). Five important domains are defined in these findings: teamwork and group processes; reflection and documentation; communication, "together (i.e. shared) knowledge"; and a general common knowledge base and ethics. The domains reflection and communication are both closely connected to theories of metacognition. 


\section{The metacognitive model as a tool for designing IPE curricula}

Reflection and metacognition are inherent in curriculum design processes for focusing attention on cause and effects in learning. In designing an IPE curriculum, this becomes apparent as one of the aims is to develop reflective and metacognitive skills.

By using the model and exemplifying learning situations early on, in the middle of and late in IPE curricula (Areskog, 2009; Wilhelmsson et al., 2009; Charles, Brainbridge and Gilbert, 2010), designers of IPE curricula will hopefully be inspired to think metacognitively and develop curricula that direct students towards becoming more reflective and thinking metacognitively.

Since our basic view of IPE is that IPE learning could be seen as a progression (Wilhelmsson et al., 2009) over time one can divide the IPE curricula into three phases; early on, in the middle of and late in the IPE curricula, as shown in table 1, 2 and 3. These tables exemplify different learning situations focusing on five important domains, which have been defined earlier in the text: teamwork and group processes, reflection and documentation, communication, shared knowledge and ethics.

When designing IPE curricula, the presented metacognitive model can be regarded as an educational process starting with defining the goals (which are closely related to the 
ethical code) and creating learning situations/actions according to Biggs theories about constructive alignment (Biggs, 2003). The components in the model can be separated, but a change in one component will influence the entire process.

In the early stages of the educational programme the personal profile component in the model must be focused on. To gain interprofessional competence is a process over time and has to start early in education (Wilhelmsson et al., 2009) with being aware of one's own personal profile, to become professional and interprofessional competent. By asking the students to write reports and other documents and collect them in a portfolio (Van Tartwijk and Driessen, 2009), they are introduced to documenting and are able to reflect on their own development (Sandars, 2009). Examples of learning situations are enhancing the students' awareness of their own learning style (Kolb, 1984) or creating case-situations/scenarios involving professional ethical dilemmas. The students have to reflect on their own norms and values with reference to the guidelines of the profession they are preparing for. By letting the students reflect on these case scenarios, they are induced to think at a deeper level and search for knowledge relevant to their own thoughts (Table 1). By presenting and discussing the reports in small groups, the students get feedback along with a systematic theoretical base (Mead, 1934).

The above IPE learning situations are examples of training in "thinking about one's own thinking" and becoming aware of metacognition processes, asking "how do I learn" and "are my own norms and values in accordance with the guidelines for the profession?" These learning situations must be documented by the students in a portfolio (Van 
Tartwijk and Driessen, 2009), so that they can track their own development, strengths and weaknesses. In the early stages of their studies students develop their professional identity and are trained in analysis, reflection, evaluation, motivation and critical thinking. With this approach, they also acquire the systematic theoretical base, set of methods and values/ethical norms of the profession. This platform can prevent stereotypical thinking and hierarchical organisational models and provide tools for effective teamwork (Allchin, Cox Dzurec and Engler, 2009).

\section{Table 1. Early in the curriculum.}

This table exemplifies learning situations early on, in the middle of and late in IPE curricula, focusing on five important domains: teamwork and group processes, reflection and documentation, communication, shared knowledge and ethics.

\begin{tabular}{|l|l|l|}
\hline Domain & Learning situation & Expected outcome \\
\hline Teamwork and group processes & $\begin{array}{l}\text { Practising and study group } \\
\text { processes }\end{array}$ & $\begin{array}{l}\text { Awareness of myself and how I } \\
\text { function in groups }\end{array}$ \\
\hline Reflection and documentation & $\begin{array}{l}\text { Introducing learning style } \\
\text { instruments in small groups and } \\
\text { discussing different learning } \\
\text { styles } \\
\text { Documentation in a portfolio }\end{array}$ & $\begin{array}{l}\text { Awarenss of my learning style, } \\
\text { how do I learn best, "thinking } \\
\text { about my own thinking", being } \\
\text { aware of metacognitive } \\
\text { processes; } \\
\text { Starting point of awareness of } \\
\text { one's own development }\end{array}$ \\
\hline Communication & $\begin{array}{l}\text { Evaluation by, for example, } \\
\text { video-taping the small group. } \\
\text { Discussing differences in } \\
\text { professional culture, language, } \\
\text { acting }\end{array}$ & $\begin{array}{l}\text { Evaluation of my own actions } \\
\text { and how the small group is } \\
\text { working } \\
\text { Awareness of the need for a } \\
\text { common language }\end{array}$ \\
\hline $\begin{array}{l}\text { Shared knowledge or general } \\
\text { common knowledge base }\end{array}$ & $\begin{array}{l}\text { Introducing general "thinking } \\
\text { models", for example, the } \\
\text { problem solving process in } \\
\text { problem-based learning (PBL) } \\
\text { the plan, do, study, act (PDSA) } \\
\text { tool and laws in health and } \\
\text { social care }\end{array}$ & $\begin{array}{l}\text { Shared use of tools when } \\
\text { discussing and acting } \\
\text { Awareness of general laws and } \\
\text { rules for all health and social } \\
\text { professions }\end{array}$ \\
$\begin{array}{l}\text { Introducing awareness of one's } \\
\text { own norms, values, ideologies } \\
\text { compared to the guidelines for } \\
\text { the shared professional value } \\
\text { platform/ethical norms }\end{array}$ & $\begin{array}{l}\text { Awareness of my personal ethics } \\
\text { and comparing it to that of my } \\
\text { future profession }\end{array}$ \\
\hline Ethics & \begin{tabular}{l} 
and \\
\hline
\end{tabular} & \\
\hline
\end{tabular}


It is very important to give students feedback and evaluate their reports, and let them know what to improve. The tutor or the other students may give this feedback. Early on in the studies it is also important to introduce general "thinking models", for example, the problem solving process in problem-based learning (Silén and Uhlin, 2008). The PDSA cycle according to Batalden (1998) is also a useful tool in teamwork.

When the students have acquired some professional knowledge and skills in the middle of their studies, the IPE curricula must be designed in relation to the circumstances. The students already have a shared platform and, in this stage of their education, they also show differences in the systematic theoretical base and set of methods, i.e. "cognitive maps" of the knowledge base underlying a particular profession (Clarke, 2006). Furthermore, there are culture patterns or "normative maps", i.e. basic values, modes of moral reasoning and methods of resolving ethical dilemmas, ethical norms, from their own programme (Drinka and Clark, 2000). In this stage, the acting/learning situation must be a "real" complex case scenario (Table 2) and has to be discussed and analysed from several perspectives (Mead, 1934), taking a holistic view and defining problems related to the phenomena.

If the interprofessional teamwork is to be successful in handling complex problems or patient cases, the interprofessional team members will need metacognitive structures. By using common tools the team-workers share a province of meaning, "together models" concerning how to think about the problem. The metacognitive structures also give the members common professional concept structures. The team-workers can discuss the 
central problem and discuss how to act for the best quality of care. Problem solving in the interprofessional team before acting, focusing on the central problem, will validate the decision-making process and also strengthen reliability concerning how to treat the patient, i.e. acting professionally and interprofessionally competent.

In the middle of their education students can reflect on their own profession as opposed to other professions and thereby discover the core and specific features of their own profession. The acting/learning situation in this step must involve more complex challenges for the students to find central parts of the case by using metacognitive tools, thinking critically and documenting and evaluating the teamwork (Table 2). An example of a learning situation is assignments where students report on a complex patient case and discuss and evaluate the reports in seminars. The students are thereby trained in reflection, documentation and evaluation in the IP groups. Ethical aspects connected to the patient case will also be addressed. The process involves comparisons of different situations involving different actors in different contexts. Hopefully, the students can thereby feel the strength of the IP group's acting out and developing professional as well as interprofessional competence.

Late in their education the students must be further trained in acting professionally and interprofessionally. The acting/learning situation can be a placement on a student training ward and being responsible for real patients (Table 3). 


\section{Table 2. In the middle of the curriculum}

This table exemplifies learning situations early on, in the middle of and late in IPE curricula, focusing on five important domains: teamwork and group processes, reflection and documentation, communication, shared knowledge and ethics.

\begin{tabular}{|c|c|c|}
\hline Domain & Learning situation & Expected outcome \\
\hline Teamwork and group processes & $\begin{array}{l}\text { Evaluation of group processes } \\
\text { Using metacognitive models: for } \\
\text { example, problem solving or } \\
\text { PDSA } \\
\text { Working together with complex } \\
\text { cases/scenarios }\end{array}$ & $\begin{array}{l}\text { Ability to give and receive } \\
\text { feedback } \\
\text { Training in using metacognitive } \\
\text { tools in the small group } \\
\text { Cognitive development in groups }\end{array}$ \\
\hline Reflection and documentation & $\begin{array}{l}\text { Documentation in a portfolio, for } \\
\text { example writing one's own report } \\
\text { of a complex case and discussion } \\
\text { and evaluation of the case at a } \\
\text { seminar }\end{array}$ & $\begin{array}{l}\text { Increased ability to reflect on } \\
\text { complex cases and awareness of } \\
\text { others' perspective } \\
\text { Increased documentation ability } \\
\text { and further personal } \\
\text { development }\end{array}$ \\
\hline Communication & $\begin{array}{l}\text { Discussing how to meet the } \\
\text { patient/client } \\
\text { Discussing how to inform the } \\
\text { patient } \\
\text { Role playing based on } \\
\text { professional/patient encounters in } \\
\text { a realistic patient/professional } \\
\text { scenario and evaluating it }\end{array}$ & $\begin{array}{l}\text { Understanding the need of using } \\
\text { different pedagogical approach to } \\
\text { different patients } \\
\text { Understanding different roles; } \\
\text { patient, practitioner, professions }\end{array}$ \\
\hline $\begin{array}{l}\text { Shared knowledge or general } \\
\text { common knowledge base }\end{array}$ & $\begin{array}{l}\text { Using knowledge acquired from } \\
\text { the first IPE curriculum and } \\
\text { becoming aware of differences in } \\
\text { knowledge }\end{array}$ & $\begin{array}{l}\text { Understanding of one's own } \\
\text { knowledge, other professions' } \\
\text { knowledge and general } \\
\text { knowledge }\end{array}$ \\
\hline Ethics & $\begin{array}{l}\text { Discussions of ethical dilemmas } \\
\text { in complex cases from different } \\
\text { professions }\end{array}$ & $\begin{array}{l}\text { Being able to discuss ethical } \\
\text { dilemmas from one's own } \\
\text { profession and see other } \\
\text { professions' perspective on the } \\
\text { situation }\end{array}$ \\
\hline
\end{tabular}

The students use all of the systematic theoretical base, set of methods and the ethical norms, both general and professional guidelines, in the IPE team to diagnose and care for the patient. On the training wards students also organise and evaluate the IP teamwork daily. Working with real patients will give the students a learning opportunity to discover the importance of a well-functioning team. By letting the students organise the work, they are induced to reflect on how to share different tasks between professions and the patients 
will be the ones to benefit from a well-functioning IP team. Well-functioning interprofessional student teams can be regarded as communities of practice (Wenger, 1998). The evaluating process after a working-day will provide good and bad examples

of how to work and possibly lead to new views on how to work tomorrow.

\section{Table 3. Late in the curriculum}

This table exemplifies learning situations early on, in the middle of and late in IPE curricula, focusing on five important domains: teamwork and group processes, reflection and documentation, communication, shared knowledge and ethics.

\begin{tabular}{|l|l|l|}
\hline Domain & Learning situation & Learning outcome \\
\hline Teamwork and group processes & $\begin{array}{l}\text { Placement on a student training } \\
\text { ward in IP teams }\end{array}$ & $\begin{array}{l}\text { Active participation in the } \\
\text { organisation and evaluation of } \\
\text { the IP team }\end{array}$ \\
\hline Reflection and documentation & $\begin{array}{l}\text { Shared patient data } \\
\text { documentation } \\
\text { Problem solving in complex } \\
\text { cases }\end{array}$ & $\begin{array}{l}\text { Deeper understanding of } \\
\text { patient/client documentation, } \\
\text { perhaps in a shared document } \\
\text { Deeper understanding of being } \\
\text { reflective, thinking critically and } \\
\text { analytically in complex cases to } \\
\text { find the core problem in the } \\
\text { patient/client situation }\end{array}$ \\
\hline Communication & $\begin{array}{l}\text { Discussions in the IP team about } \\
\text { the patient/client situation, the } \\
\text { central problem, treatment and } \\
\text { rehabilitation }\end{array}$ & $\begin{array}{l}\text { Understanding how important it } \\
\text { is to have a common language, } \\
\text { metacognitive tools and a } \\
\text { common platform to facilitate } \\
\text { communication }\end{array}$ \\
\hline $\begin{array}{l}\text { Shared knowledge or general } \\
\text { common knowledge base }\end{array}$ & $\begin{array}{l}\text { Discussions in the IP team about } \\
\text { knowledge, skills, culture, and } \\
\text { roles in different professions }\end{array}$ & $\begin{array}{l}\text { Understanding one's own and } \\
\text { others' knowledge and skills and } \\
\text { differences in the province of } \\
\text { shared meanings }\end{array}$ \\
\hline Ethics & $\begin{array}{l}\text { Discussions in the IP team of real } \\
\text { patient/client situation and } \\
\text { decision-making }\end{array}$ & $\begin{array}{l}\text { Understanding how to use } \\
\text { general ethical and professional } \\
\text { guidelines in real cases } \\
\text { Acting for the best } \\
\text { treatment/rehabilitation of the } \\
\text { patient/client }\end{array}$ \\
\hline
\end{tabular}




\section{CONCLUDING COMMENTS}

Is there a need for metacognitive thinking in teamwork? All professionals in health and social care have their own culture, language, knowledge and skills. Simply letting students work in teams does not necessarily means that they are actually working as a team. If the team has common tools such as "metacognitive thinking models", this will facilitate communication and understanding in the team. An example of good teamwork could be a football team. They are trained to be a team, but they also work on their own individual strengths and weaknesses to fit in with the team. The role of the coach is to evaluate the team and individual players before, during and after a match, indirectly by using metacognitive thinking.

This article points out the need for using metacognition in interprofessional education. The metacognitive model presented could contribute to understanding the complexity of interprofessional competence. However, a model is a model and can never fully cover a complex situation and is always a simplifier of reality.

The construction of IP curricula also has a key role to play if the IPL training is to be successful. The IP learning situations exemplified in this article may be helpful tools for IPE educators and for developing professional practitioners with a focus on the patient's problem from more than one profession's perspective (Mead, 1934; Hultberg, Rosenberg, Thorbenberg, Nordholm, Elzinga and Brogren, 1998; Wackerhausen, 2009). In the end, the overall winner of interprofessional practice has to be the patient. 


\section{Acknowledgments}

We want to express our gratitude for the intellectual support of this paper from the staff and teachers involved in the interprofessional education at the Faculty of Health Sciences at Linköping University, Sweden.

\section{Declaration of interest}

The authors report no conflicts of interest. The authors alone are responsible for the content and writing of the paper.

\section{REFERENCES}

Areskog, N-H. (2009). Undergraduate interprofessional education at the Linköping

Faculty of Health Sciences - How it all started. Journal of Interprofessional Care, 23(6), $442-447$

\footnotetext{
Allchin, L., Cox Dzurec, L. and Engler, A. J. (2009). Psychological type and explanatory style of nursing students and clinical faculty. Journal of Nursing Education, 48(4), 196202.
} 
Barr, H., Koppel, I., Reeves, S., Hammick, M. and Freeth, D. (2005). Effective Interprofessional Education: Argument, Assumption \& Evidence. Blackwell Publishing, Oxford.

Barry, J., Gurland, B.J., Gurland, R. V., Mitty, E., Toner, J. (2009). The choices, choosing model of quality of live: Clinical evaluation and intervention. Journal of Interprofessional Care, 23(2), 110-120.

Batalden, P. B. (1998). If improvement of the quality and value of health and health care is the goal, why focus on health professional development? Quality Management in Health Care, (2), 52-61.

Biggs, J. (2003). Teaching for Quality Learning at University. Open University Press, London. Second Edition. The Society for Research into Higher Education.

Charles, G., Bainbridge, L., Gilbert, J. (2010) The University of British Columbia model of interprofessional education. Journal of Interprofessional Care, 24(1), 9-18.

Clark, P. G. (2006). What would a theory of interprofessional education look like? Some suggestions for developing a theoretical framework for teamwork training. Journal of Interprofessional Care. 20(6), 577-89. 
Clark, P. G. (2009). Reflecting on reflection in interprofessional education. Implications for theory and practice. Journal of Interprofessional Care, 23(3), 213-223.

Cross, P. (1982). Adults as Learners. San Francisco, California. Jossey-Bass Publishers.

Drinka, T. J. K., \& Clark, P. G. (2000). Health Care Teamwork: Interdisciplinary Practice and Teaching. Westport, CT: Auburn House/Greenwood.

Flavell, J. H. (1979). Metacognition and cognitive monitoring: A new area of cognitivedevelopmental inquiry. American Psychologist, 34, 906-911.

Flavell, J. H. (1987). Speculations about the nature and development of metacognition. In F. E. Weinert \& R. H. Kluwe (Eds.), Metacognition, Motivation and Understanding (pp. 21-29). Hillside, New Jersey: Lawrence Erlbaum Associates.

Forslund, K. (2001) Development of Professional Competence. Department of Pedagogy and Physiology, LiU-PEK-R-168, Linköping University.

Hartman, S., Lundgren, U.P. and Hartman R. M. (2004). John Dewey. Individual, School and Society. Edition 4, Natur och Kultur, Stockholm, Sweden.

Headrick, L., Wilcock, P., Batalden, P. (1998) Interprofessional working and continuing medical education. Biomedical Medicine Journal, 7(316), 771-774. 
Hultberg, J., Rosenberg, C., Thorpenberg, S., Nordholm, L., Elzinga, A., Brogren, P-O. Samuelsson, B. (1998). A model for the study of research and education? in a transdisciplinary context. Knowledge, Technology and Policy, 11(1\&2), 167-190.

Kolb, D. A. (1984). Experimental Learning. Englewood Cliffs, NJ: Prentice-Hall.

Livingston, J. (1997) Metacognition: An Overview. State University of New York at Buffalo. http://www.julianhermida.com/metacognition.pdf

Mead, G. H. (1934). Mind Self \& Society. The University of Chicago Press. US.

Olckner, L., Gibbs, T.J., Duncan, M. (2007). Developing health science students into integrated health professionals: a practical tool for learning. BMC Medical Education 7(45), $1-7$.

Parsell, G. \& Bligh, J. (1998). Educational principles underpinning successful shared learning. Medical Teacher, 20, 522 - 529.

Petrie, H. G. (1976). Do you see what I see? The epistemology of interdisciplinary inquiry. The Journal of Aesthetic Education, 10, 29-43. 
Sandars, J. (2009). The use of reflection in medical education: AMEE Guide No. 44, Medical Teacher, 31(8), 685 - 695.

Schön, D.A. (1987). Educating the Reflective Practitioner. San Francisco: Jossey-Bass.

Stephenson, R. (2004). Using a complex model of human behaviour to help interprofessional clinical reasoning. International Journal of Therapy and Rehabilitation, 11(4), 168-174.

Silén, C. \& Uhlin, L. (2008) Self-directed learning - an issue for students and the faculty! Teaching in Higher Education, 13(4), 461-475.

Wackerhausen, S. (2009). Collaboration, professional identity and reflection across boundaries. Journal of Interprofessional Care, 23, 1-19.

Van Tartwijk, J. and Driessen, E. W. (2009). Portfolios for assessment and learning: AMEE Guide no. 45, Medical Teacher, 31(9), 790801.

Walsh, C. L., Gordon, F. M., Marshall, M., Wilson, F., Hunt, T. (2008). Interprofessional Capability: A Developing Framework for Interprofessional Education. Combined Universities Interprofessional Learning Unit, Medical School, Beech Hill Road, Sheffield $U K$. 
Wenger, E. (1998). Communities of Practice: Learning, Meaning and Identity.

Cambridge, England: Cambridge University Press.

Wilhelmsson, M., Pelling, S., Ludvigsson, J., Dahlgren, L.O., Hammar, M., Faresjö, T. (2009). Twenty years experience of interprofessional education in Linköping - groundbreaking and sustainable. Journal of Interprofessional Care, 23 (2),1-13.

Wood, V., Flavell, A., Vanstolk, D., Brainbridge, L., Nasmith, L. (2009) The road to collaboration: Developing an interprofessional competency framework. Journal of Interprofessional Care, 23(6), 621-620.

World Health Organisation, Declaration of Alma-Ata. International Conference on Primary Health Care, WHO; 1978, Alma-Ata, USSR.

World Health Organisation. Learning together to work together for health: Technical Report Series 769, WHO; 1988, Geneva, Switzerland.

World Health Organisation. Working Together for Health. Report 2006;

The $59^{\text {th }}$ World Health Assembly (WHA.59.23). 